\title{
Characteristics of Side-by-Side Vehicle Crashes and Related Injuries as Determined Using Newspaper Reports from Nine U.S. States
}

\author{
Charles A. Jennissen ${ }^{1, *}$, Karisa K. Harland ${ }^{2,+}$ and Gerene M. Denning ${ }^{2,+}$ \\ 1 Department of Emergency Medicine, University of Iowa Carver College of Medicine, 200 Hawkins Drive, \\ Iowa City, IA 52242, USA \\ 2 Department of Emergency Medicine, University of Iowa Hospital and Clinics, Iowa City, IA, 52242, USA; \\ kari-harland@uiowa.edu (K.K.H.); gerene-denning@uiowa.edu (G.M.D.) \\ * Correspondence: charles-jennissen@uiowa.edu; Tel.: +1-319-384-8468; Fax: +1-319-353-7006 \\ + These authors contributed equally to this work.
}

Academic Editor: Raphael Grzebieta

Received: 31 October 2015; Accepted: 28 March 2016; Published: 5 April 2016

\begin{abstract}
Side-by-side (SxS) vehicles have become increasingly popular, but there are few reports on injury epidemiology. Newspaper reports of SxS and all-terrain vehicle (ATV) crashes were analyzed for nine U.S. states from 2009 to 2011, including comparisons between the two vehicle types. Seventy-nine SxS crashes involving 104 injured victims were identified; three-fourths were males. There was a relatively high percentage of injured passengers (37\%), and a higher proportion of female victims were passengers as compared to males $(p=0.015)$. Children $<16$ years of age were $44 \%$ of those injured and had the highest proportion of both passenger and operator victims as compared to other age groups. Over half of the crashes occurred on roadways; nearly two-fifths occurred at night. As compared to adults, a lower percentage of crashes involving youth were at night $(p=0.0037)$ but the percentages on roadways were similar. Only one in five roadway SxS crashes involved a collision with a motorized vehicle. Rollovers were the most common mechanism (50\%). Two-thirds of victims were ejected, and one-half were struck or pinned by the vehicle. Twenty-eight deaths $(27 \%)$ were reported. Although most current SxSs have roll bars, lack of safety belt use has likely reduced their benefit. Children should be prohibited from operating SxSs.
\end{abstract}

Keywords: side-by-side vehicle; utility task vehicle; recreational off-road vehicle; all-terrain vehicle; injury prevention; safety; pediatric; roadway; rollover; crash

\section{Introduction}

Side-by-side (SxS) vehicles have become increasingly popular over the past decade [1,2], and consequently SxS-related deaths and injuries have become an emerging public health issue for which there are few published reports. One of the challenges in studying this issue is the variety of terms used to describe these vehicles, terms that are often used incorrectly.

SxSs are motorized vehicles designed for off-road use and have four or more deep-treaded pneumatic tires, bench or bucket seating for two or more occupants, a steering wheel for directional control, and foot pedals for acceleration and braking. Recreational off-highway vehicles (ROVs) are SxSs that have maximum speeds of at least 30 miles per hour (mph) [3]. Although the first ROVs were marketed more for their utilitarian features, the recreational aspects have become a major emphasis in recent years. Several varieties of ROVs now exist including sport, multi-purpose and utility ROVs. Those with more work-related capability have bigger cargo beds able to handle larger loads and usually lower maximum speeds. The opposite is true for sports models. 
ROVs are sometimes called UTVs an acronym most commonly standing for utility task vehicle, but has also been translated as utility terrain vehicle, utility type vehicle and utility vehicle-all referring to the same classification of vehicles. All UTVs are SxSs, but according to Society of Automotive Engineering (SAE) Institute standards, low-speed utility vehicles are distinguished from ROVs in that they have maximum speeds of $25 \mathrm{mph}$ or less [3]. All ROVs, but only some UTVs, have rollover protective structures (ROPS) and personal restraint devices, either seat belts or harness systems.

Often, SxSs are referred to as all-terrain vehicles (ATVs). Although ATVs and SxSs are both designed for off-road use, they are very different in design. Unlike SxSs, ATVs have a straddle seat, handle bars for steering, and hand controls for throttle and brakes. ATVs also have no ROPS or seat belts, although the Polaris Ace introduced in 2014 is an exception to this rule [4]. Almost all ATVs are for use by an operator only, not for carrying passengers. In addition, the operator is required to do "active riding" in which shifting of the body and maintaining grip and footing are required to maintain vehicle-operator stability and prevent loss of control [5]. SxSs are wider and heavier than ATVs and the motion of occupants has very little effect on overall vehicle stability and control. Thus, the mechanism and injuries sustained by victims in SxS-related crashes may be quite different from those reported for ATV crashes.

Newspaper reports have been utilized to provide surveillance data on a number of injury-related problems including fires, drowning, farm injuries, motor vehicle crashes, and gun violence [6-18]. From our work with ATVs $[19,20]$, we recognized the difficulty in trying to differentiate off-road vehicles from one another using hospital data, as these vehicles were all designated by the same e-code (supplemental codes in the International Classification of Diseases used by health care providers to classify external causes of injury). As an alternative, we hypothesized that newspaper articles of SxS-related events could provide insights on this emerging problem. Our study objective was to evaluate SxS crashes as reported in newspapers with respect to demographics, crashes and injuries.

\section{Methods}

\subsection{Data Extraction and Coding}

Newspaper reports of ATV and SxS crashes were collected prospectively via a press clipping service for nine states in the Midwest/Great Plains region of the U.S. from 2009 to 2011. These states included: Iowa, Illinois, Kansas, Minnesota, Missouri, Nebraska, North Dakota, South Dakota, and Wisconsin. A report was determined to involve a SxS by the following criteria: (1) the article specifically mentioned a make and model known to be a SxS; (2) the vehicle was stated as being a SxS, UTV or ROV in the report; or (3) the vehicle was identified as an ATV but (a) was described as having seatbelts, roll bars, a steering wheel, and/or a rear cargo bed; or (b) the article had other descriptive vehicle information indicative of a SxS and no other information supporting the identification of the vehicle as an ATV. There were two vehicle crash reports that met the last criteria; the first described the vehicle as having six wheels (all ATVs have three or four wheels) and in the second, the article described that after the crash "the passengers exited the vehicle" (one does not exit the straddle seat of an ATV). The University of Iowa Institutional Review Board approved this study.

A coding system was created that included variables related to persons (e.g., sex, age, seating position), vehicles (e.g., model, description), crashes (e.g., mechanism, light conditions), and injury mechanism (e.g., fall/ejection) and severity (e.g., fatality). Research team members were extensively trained in the coding system with ongoing quality control by the principal investigators during the training process. Data were extracted by careful reading of the newspaper reports and coded for all variables available in the press clipping by three team members. An additional research assistant performed quality control and verified all data. Coding discrepancies or questions regarding entries were resolved in collaboration with the principal investigators.

The mechanism of injury was coded as a sequence of events with the "primary mechanism" being defined as the first significant event in the cascade of events leading to the patient's traumatic injury. Mechanisms were grouped first at the highest level as non-collision, collision with an object 
other than a motorized vehicle, and collision with a motorized vehicle. Primary non-collision events were further categorized as rollover, the vehicle going airborne due to a man-made ramp or terrain feature, and falls/ejections (including self-ejections) that were not secondary to a rollover, collision, or vehicle airborne event. For example, an ATV that had a side rollover with the rider subsequently being ejected to the side and striking a tree with his head would be coded a "rollover" as the primary crash mechanism. Conversely, if the rider fell or was ejected from the ATV as the only injury mechanism or prior to the vehicle rolling over or colliding with an object, then the primary crash mechanism would be coded as a "fall/ejection". Analysis was performed for falls/ejections as the primary mechanism, as well as for all rollovers and all falls/ejections that were part of the sequence of events.

\subsection{Data Analysis}

All statistical analyses were performed using SAS ${ }^{\circledR}$ software, Version 9.2 of the SAS System for Microsoft (SAS Institute Inc., Cary, NC, USA) or the VassarStats Website for Statistical Computation (http://www.vassarstats.net). All tests were two-tailed and significance was defined as a $p$-value of $<0.05$. Comparisons of proportions for categorical variables were done using the chi square test, and unadjusted odds ratios (OR) and 95\% confidence intervals (95\% CI) for $2 \times 2$ comparisons were determined. The small number of cases precluded multivariable regression analysis.

\section{Results}

\subsection{Demographics: SxS vs. ATV}

A total of 1299 crashes of ATVs or SxSs and 1543 injured riders were identified in newspaper reports from nine states from 2009 to 2011. Of these, 79 crashes and 105 injured riders involved SxSs. Over 70\% of those injured in SxS events were males, a similar proportion as that seen in ATV crash press clippings. See Table 1. Victims ranged in age from 7 to 82 years old with a mean and standard deviation of $29 \pm 20$ years old and a median age of 20. Forty-four percent of SxS-related injuries involved children $<16$ years of age. A significantly higher percentage of $S x S$ crashes involved a child, as compared to ATV crashes, OR 2.45, 95\% CI 1.60-3.77, $p<0.0001$. Seat belt and helmet use were not well documented in the articles. Six SxS victims were documented as wearing their seat belt, and only three were reported as wearing a helmet. SxS crashes resulted in a high proportion of passenger victims. Of those for which seating position was documented, injured passengers made up a significantly higher percentage of the SxS victims than that seen for ATV victims in press reports, OR $2.15,95 \%$ CI 1.33-3.47, $p=0.0014$.

A higher proportion of riders in reported SxS crashes were killed than those in ATV crashes, a difference trending toward but not reaching significance, $p=0.075$. Similarly, when SxS drivers and passengers were compared, the proportion of fatalities for drivers (18 of 51,35\%) was higher than for passengers ( 4 of $27,15 \%$ ), but the difference did not reach significance, $p=0.068$. 
Table 1. Injured rider characteristics of SxS as compared to ATV crashes documented in press clippings from nine U.S. states (2009-2011). ${ }^{1}$ SxS, $N=105$ injured riders; ATV, $N=1438$ injured riders.

\begin{tabular}{|c|c|c|c|c|}
\hline \multirow{2}{*}{\multicolumn{2}{|c|}{ Injured Rider Characteristics }} & \multicolumn{2}{|c|}{ Vehicle Type } & \multirow{2}{*}{$p$-Value ${ }^{3}$} \\
\hline & & $\mathrm{SxS} n(\mathrm{Col} \%)^{2}$ & $\operatorname{ATV} n(\mathrm{Col} \%)^{2}$ & \\
\hline \multirow{2}{*}{ Sex } & Male & $73(72 \%)$ & $1008(74 \%)$ & \multirow{2}{*}{0.56} \\
\hline & Female & $29(28 \%)$ & $73(26 \%)$ & \\
\hline \multirow{4}{*}{ Age } & $<16$ & $41(44 \%)$ & $301(24 \%)$ & \multirow{4}{*}{$<0.0001$} \\
\hline & $16-35$ & $19(20 \%)$ & $520(42 \%)$ & \\
\hline & $36-65$ & $25(27 \%)$ & $360(29 \%)$ & \\
\hline & $>65$ & $8(9 \%)$ & $56(5 \%)$ & \\
\hline \multirow{2}{*}{ Helmet } & Yes & $3(13 \%)$ & $75(20 \%)$ & \multirow{2}{*}{0.59} \\
\hline & No & $20(87 \%)$ & $301(80 \%)$ & \\
\hline \multirow{2}{*}{ Seating position } & Driver & $51(63 \%)$ & $710(79 \%)$ & \multirow{2}{*}{0.0014} \\
\hline & Passenger & $30(37 \%)$ & $194(22 \%)$ & \\
\hline \multirow{2}{*}{ Fatally injured } & Yes & $29(28 \%)$ & $292(20 \%)$ & \multirow{2}{*}{0.075} \\
\hline & No & $56(72 \%)$ & $1146(80 \%)$ & \\
\hline
\end{tabular}

Notes: ${ }^{1}$ Abbreviations: $N=$ total number of injuries; $n=$ number of injuries in analysis subgroup; $\mathrm{SxS}=$ side-by-side; $\mathrm{ATV}=$ all-terrain vehicle $\mathrm{Col}=$ column $;{ }^{2}$ Column total may not equal total $\mathrm{N}$ because of missing data; ${ }^{3}$ Chi square comparison of proportions by vehicle type.

\subsection{SxS Crashes and Seating Position}

Eighty-two percent of injured SxS drivers were male. See Table 2. Injured females were a significantly higher proportion of passengers than of drivers, OR 3.9, 95\% CI 1.38-11.22, $p=0.009$. Children $<16$ years of age comprised almost half of both driver and passenger SxS crash victims, and there was no difference in seating position by age. Of youth SxS victims $<16$ years of age, two-thirds of them were the operator of the vehicle at the time of the crash.

Table 2. Injured rider characteristics by seating position of SxS crashes documented in press clippings from nine U.S. states (2009-2011). ${ }^{1}$ SxS, $N=105$ injured riders.

\begin{tabular}{|c|c|c|c|c|}
\hline \multirow{2}{*}{\multicolumn{2}{|c|}{ Injured Rider Characteristics }} & \multicolumn{2}{|c|}{ Seating Position } & \multirow{2}{*}{$p$-Value ${ }^{3}$} \\
\hline & & Driver $n(\mathrm{Col} \%)^{2}$ & Passenger $n(\mathrm{Col} \%)^{2}$ & \\
\hline \multirow[b]{2}{*}{ Sex } & Male & $41(82 \%)$ & $14(54 \%)$ & \multirow[b]{2}{*}{0.009} \\
\hline & Female & $9(18 \%)$ & $12(46 \%)$ & \\
\hline \multirow{4}{*}{ Age } & $<16$ & $21(45 \%)$ & $10(46 \%)$ & \multirow{4}{*}{0.69} \\
\hline & $16-35$ & $10(21 \%)$ & $6(27 \%)$ & \\
\hline & $36-65$ & $9(19 \%)$ & $5(23 \%)$ & \\
\hline & $>65$ & $7(15 \%)$ & $1(4 \%)$ & \\
\hline
\end{tabular}

Notes: ${ }^{1}$ Abbreviations: $N=$ total number of injuries; $n=$ number of injuries in analysis subgroup; $\mathrm{SxS}=$ side-by-side; $\mathrm{Col}=$ column; ${ }^{2}$ Column total may not equal total $N$ because of missing data; ${ }^{3}$ Chi square comparison of proportions by SxS seating position.

\subsection{Crash Characteristics: $S x S$ vs. ATV}

Seasonal differences were seen in the proportions of crashes for the two vehicle types, with SxSs having higher percentages than ATVs during the fall months as compared to the rest of the year, OR 1.91, 95\% CI 1.17-3.13, $p=0.009$. See Table 3. Similar to ATVs, a little more than half of the SxS crashes occurred on the weekend (Saturday and Sunday). Almost half of SxS crashes occurred between 4 P.M. and 8 P.M., a much higher proportion than for ATVs when compared to all other times of the day, OR 1.98, 95\% CI 1.18-3.33, $p=0.008$. Similar percentages of SxS (39\%) and ATV (38\%) crashes occurred during compromised light conditions (dusk, night, dawn). A lower proportion of SxS crashes involving child victims (4 of 24, 17\%) occurred under limited light conditions, as compared to SxS 
crashes involving adults ( 18 of $33,55 \%$ ), OR $0.17,95 \%$ CI $0.05-0.60, p=0.004$. Over half of both SxS crashes and ATV crashes occurred on public roads. There was no difference in the proportion of SxS crashes on roadways versus off-road when comparing crashes involving a child victim $(57 \%, 13$ of 23$)$ with those involving adult victims only $(55 \%, 16$ of 29$), p=0.69$.

Table 3. Crash Characteristics for SxS as compared to ATV crashes documented in press clippings from nine states U.S. states (2009-2011). ${ }^{1}$ SxS, $N=79$ crashes; ATV, $N=1220$ crashes.

\begin{tabular}{|c|c|c|c|c|}
\hline \multirow{2}{*}{\multicolumn{2}{|c|}{ Crash Characteristics }} & \multicolumn{2}{|c|}{ Vehicle Type } & \multirow{2}{*}{$p$-Value ${ }^{3}$} \\
\hline & & $\operatorname{SxS} n(\mathrm{Col} \%)^{2}$ & $\operatorname{ATV} n(\mathrm{Col} \%)^{2}$ & \\
\hline \multirow{4}{*}{$\begin{array}{l}\text { Month of } \\
\text { Crash }\end{array}$} & June-Aug & $23(30 \%)$ & $529(44 \%)$ & \multirow{4}{*}{0.0007} \\
\hline & Sept-Nov & $26(34 \%)$ & $254(21 \%)$ & \\
\hline & Dec-Feb & $0(0 \%)$ & $97(8 \%)$ & \\
\hline & March-May & $28(36 \%)$ & $328(27 \%)$ & \\
\hline \multirow{2}{*}{$\begin{array}{l}\text { Crash on } \\
\text { Weekend }\end{array}$} & Yes (Saturday/Sunday) & $32(53 \%)$ & $417(52 \%)$ & \multirow{2}{*}{0.83} \\
\hline & No & $28(47 \%)$ & $387(48 \%)$ & \\
\hline \multirow{6}{*}{$\begin{array}{c}\text { Time of } \\
\text { Crash }\end{array}$} & Midnight-3:59 A.M. & $4(7 \%)$ & $81(8 \%)$ & \multirow{6}{*}{0.032} \\
\hline & 4 A.M.-7:59 A.M. & $0(0 \%)$ & $28(3 \%)$ & \\
\hline & 8 A.M.-11:59 A.M. & $7(11 \%)$ & $73(7 \%)$ & \\
\hline & Noon-3:59 P.M. & $17(27 \%)$ & $308(31 \%)$ & \\
\hline & 4-7:59 P.M. & $29(47 \%)$ & $302(31 \%)$ & \\
\hline & 8-11:59 P.M. & $5(8 \%)$ & $192(20 \%)$ & \\
\hline \multirow{2}{*}{ Lighting } & Day & $38(61 \%)$ & $636(62 \%)$ & \multirow{2}{*}{0.86} \\
\hline & Dusk/Night/Dawn & $24(39 \%)$ & $383(38 \%)$ & \\
\hline \multirow{2}{*}{ Location } & Roadway & $31(54 \%)$ & 107 (57\%) & \multirow{2}{*}{0.77} \\
\hline & Off-road & $26(46 \%)$ & $82(43 \%)$ & \\
\hline \multirow{5}{*}{$\begin{array}{c}\text { Primary } \\
\text { Mechanism }\end{array}$} & Collision w/object & $21(34 \%)$ & $318(32 \%)$ & \multirow{5}{*}{0.043} \\
\hline & Vehicle airborne & $0(0 \%)$ & $38(4 \%)$ & \\
\hline & Rollover & $32(53 \%)$ & $356(36 \%)$ & \\
\hline & Fall/Ejection & $2(3 \%)$ & $88(9 \%)$ & \\
\hline & Collision w/MV & $6(10 \%)$ & $183(19 \%)$ & \\
\hline \multirow{4}{*}{$\begin{array}{l}\text { Number of } \\
\text { Passengers }\end{array}$} & None & $23(34 \%)$ & 607 (67\%) & \multirow{4}{*}{$<0.0001$} \\
\hline & One & $35(52 \%)$ & $261(29 \%)$ & \\
\hline & Two & $5(8 \%)$ & $18(2 \%)$ & \\
\hline & Three or more & $4(6 \%)$ & $14(2 \%)$ & \\
\hline
\end{tabular}

Notes: ${ }^{1}$ Abbreviations: $N=$ total number of crashes; $n=$ number of crashes in analysis subgroup; SxS = side-by-side; ATV = all-terrain vehicle; $\mathrm{Col}=$ column; MV = motorized vehicle $;{ }^{2}$ Column total may not equal total $\mathrm{N}$ because of missing data; ${ }^{3} \mathrm{Chi}$ square comparison of proportions by vehicle type; ${ }^{4}$ Three SxS crashes and 31 ATV crashes had other mechanisms that did not fit into major categories.

A number of differences between SxSs and ATVs were observed for the primary mechanism. For example, a rollover was the primary mechanism in $53 \%$ of SxS crashes but only $36 \%$ of ATV crashes. Conversely, $4 \%$ of ATV crashes involved the vehicle going airborne, whereas no reports were found where SxSs had this as their primary mechanism. The proportion of SxS crashes where there was a collision with a motorized vehicle was about half that of ATVs. In addition, two-thirds of the $\mathrm{SxS}$ crashes had passengers in the vehicle at the time of the crash, twice the proportion observed for ATVs (33\%).

\subsection{SxS Injury Mechanisms and Fatalities}

Over two-thirds of SxS crashes included a fall/ejection from the vehicle in the sequence of events. See Table 4. Almost half of all SxS crash victims were struck or pinned by the vehicle. Twenty-eight SxS crash victims were noted to have died from their injuries in the newspaper reports. Of these, $66 \%$ were males and $44 \%$ were children. See Table 5 . Half of all fatalities involved a rollover as their primary 
crash mechanism, and $67 \%$ involved a fall or ejection from the vehicle at some time during the crash event. Over $60 \%$ of fatality victims were killed on public roads and $41 \%$ under limited light conditions.

Table 4. Injury mechanisms of SxS crashes documented in press clippings from nine states U.S. states (2009-2011). ${ }^{1}$ SxS, $N=79$ crashes.

\begin{tabular}{ccc}
\hline Injury Mechanisms & & SxS $\boldsymbol{n}$ (Col \%) $^{2}$ \\
\hline \multirow{2}{*}{ All Falls/Ejections } & Yes & $30(67 \%)$ \\
& No & $15(33 \%)$ \\
\hline \multirow{2}{*}{ Struck/Pinned by Vehicle } & Yes & $24(49 \%)$ \\
& No & $25(51 \%)$ \\
\hline
\end{tabular}

Notes: ${ }^{1}$ Abbreviations: $N=$ total number of crashes; $n=$ number of crashes in analysis subgroup; $\mathrm{SxS}=$ side-by-side; $\mathrm{Col}=$ column; ${ }^{2}$ Column total may not equal total $N$ because of missing data.

Table 5. Characteristics of fatalities in SxS crashes documented in press clippings from nine states U.S. states (2009-2011). ${ }^{1}$ SxS, $N=79$ crashes $/ 105$ injured riders, 28 fatalities.

\begin{tabular}{|c|c|c|}
\hline \multicolumn{2}{|c|}{ Variable } & \multirow{3}{*}{$\begin{array}{c}\text { Fatalities } \% \text { of Group } \\
66 \% \\
34 \%\end{array}$} \\
\hline S & Male & \\
\hline sex & Female & \\
\hline \multirow{4}{*}{ Age } & $<16$ & $44 \%$ \\
\hline & $16-35$ & $23 \%$ \\
\hline & $36-65$ & $29 \%$ \\
\hline & $>65$ & $5 \%$ \\
\hline \multirow{2}{*}{ Seating } & Driver & $56 \%$ \\
\hline & Passenger & $44 \%$ \\
\hline \multirow{5}{*}{ Primary Mechanism } & Collision w/Object & $34 \%$ \\
\hline & Rollover & $50 \%$ \\
\hline & Fall/Ejection & $5 \%$ \\
\hline & Collision w/MV & $5 \%$ \\
\hline & Other & $6 \%$ \\
\hline \multirow{2}{*}{ Fall/ejection (All) } & No & $33 \%$ \\
\hline & Yes & $67 \%$ \\
\hline \multirow{2}{*}{ Location } & Roadway & $38 \%$ \\
\hline & Off-Road & $62 \%$ \\
\hline \multirow{2}{*}{ Lighting } & Day & $59 \%$ \\
\hline & Dusk/Night/Dawn & $41 \%$ \\
\hline
\end{tabular}

Note: ${ }^{1}$ Abbreviations: SxS = side-by-side.

\section{Discussion}

\subsection{Growing Side-by-Side Use}

SxSs in the form of low-speed UTVs have been available since the early 1980s. According to data obtained from Power Products Marketing by the Consumer Product Safety Commission (CPSC), low-speed UTV sales in the U.S. peaked at about 150,000 units in 2007 [1]. ATV sales also reached their highest sales about that same time with 1.1 million vehicles sold in the U.S. in 2006 [1]. Sales of both vehicles have decreased substantially since that time. Concomitantly, the number of ATV fatalities in the U.S. as monitored by the CPSC, have leveled off or even decreased since the drop-off in ATV sales [21].

In contrast, ROV sales have skyrocketed in the past decade [1]. The first ROV, the Kawasaki Mule, was introduced in 1988 [22]. This vehicle, and others that were similar, were touted by their manufacturers for their utilitarian versatility. They became popular in work settings, but sales were 
only about 20,000 units in 2003 [1]. However, in 2004, the Yamaha Rhino was introduced as designed for both recreational and occupational use [22]. The success of the Rhino motivated other power sport companies to create their own ROV innovations. Soon, manufacturers were producing ROVs designed primarily for recreational riding and narrow enough to negotiate the 50-inch width of many established trails. 234,000 ROVs were sold in the U.S. by 20 different manufacturers in 2013, more than 100 times that sold in 2003 [1]. The CPSC estimated there were 1.2 million ROVs in use in the U.S. by the end of 2013 [1].

\subsection{Recognition of Public Health Issue}

Not long after being introduced, a number of serious injuries and fatalities related to the Yamaha Rhino were being reported [23]. The CPSC investigated many of these crash events which resulted in a repair program that increased the lateral stability of the vehicle and changed the handling characteristics from a propensity to oversteer to one of understeer [1]. In the three years prior to the initiation of the repair program in March 2009, there were 155 Rhino-related crash reports received by the CPSC. In the three years post-repair, the number of incidents decreased to 53 [1].

In November 2014, the CPSC published in the Federal Register a notice of proposed rulemaking (NPR) for standards to improve the safety of ROVs [1]. The NPR "would establish requirements for lateral stability, vehicle handling, and occupant protection performance, as well as information requirements." These proposed mandatory standards have met significant opposition from the industry and their adoption as of March 2016 is in jeopardy. As part of their investigation of the hazard patterns associated with ROVs, the CPSC analyzed 428 ROV-related crashes involving 231 fatalities and 388 injuries that they had received from January 2003 through December 2011 [1]. Beyond this, there has been little published on the demographics and crash characteristics of SxS-related incidents.

\subsection{Demographics of SxS Crashes}

In our study, nearly three-quarters of injured SxS crash victims were male. This is somewhat lower than the proportion reported for ATV crashes, which is usually over $85 \%$ [19,24-26]. Consistent with its design for multiple riders, $\mathrm{SxS}$ crashes had a significantly higher percentage of injured passengers than newspaper reports of ATV crashes, and than previous studies of ATV-related deaths and injuries (passengers $\sim 15 \%$ of victims) $[19,24-26]$. In addition, the vast majority of injured SxS operators were male $(81 \%)$, but over two-fifths of injured passengers were female. This is similar to ATV crashes, where females were $45 \%$ and $49 \%$ of passenger deaths and injuries, respectively [19,24].

The percentage of SxS crash victims less than 16 years of age (44\%) was significantly higher than that seen in the press clippings of ATV-related events, and as compared to other ATV studies where youth victims were found to be around one-quarter of deaths and $24 \%-29 \%$ of those injured $[19,21,24]$.

This strikingly high percentage of injured youth in SxS crashes is very concerning. Children under sixteen years of age are prohibited by the manufacturer from operating ROVs, and consumers are warned in the owner's manuals and by decals on the vehicle to this regard. Of SxS operator victims in our study, $45 \%$ were $<16$ year of age, a number higher than the $21 \%$ and $25 \%$ of youth operators seen in fatal and non-fatal ATV crashes, respectively $[19,24,25]$. In many of these cases, the child was likely too small to have the seat belt on properly and still be able to operate the foot pedal.

Children $<16$ years are not only supposed to be restricted from driving ROVs, but manufacturers also discourage transporting them as passengers. There are currently no standards for the safe restraint of children in ROVs. Manufacturers do not provide instructions for the use of car seats and booster seats as they do not consider this safe use of the vehicle. In addition, an important aspect of riding on SxSs safely is being able to hold onto the handle grips to help maintain the head and torso inside the protective zone created by the ROPS. These are usually located on the anterior roll bar for a passenger and usually beyond the reach of restrained children. ROV instructional manuals state that each passenger must be able to sit with their back against the seat, their feet flat on the floor, and a 
hand on the handgrip or handhold [27-29]. Some ROV manufacturers state that no child under the age of 12 should ride in their vehicles [27,28].

\subsection{Crash and Injury Mechanisms}

\subsubsection{Rollovers}

Similar to ATVs, a majority of the SxS crashes were rollovers. The CPSC in their analysis of collected ROV incidents found that about two-thirds of the cases, including about $90 \%$ of those severely injured were in a lateral rollover [1]. Of those for which the terrain was known, just over half occurred on flat terrain [1]. In addition to their experience with the Yamaha Rhino, this helped spur the CPSC to consider ROV standards to improve lateral stability and prevent oversteer. Investigators at the University of New South Wales have been developing testing to evaluate the safety of ROV and ATV models in order to inform consumers, and with the hope that safety ratings will encourage manufacturers to engineer improved safety design of off-road vehicles as has occurred in the automobile industry [30].

\subsubsection{Use of Restraints}

The documentation in newspaper reports regarding seat belt use was extremely limited. Only six injured riders were documented as having been using the SxS restraint device. We hypothesize that the vast majority of $S x S$ riders for which this information was missing were not restrained. For those whose seat belt use was known in ROV incidents received by the CPSC, 73\% overall were not wearing seat belts and $91 \%$ of fatality victims were not [1]. Consistent with this, the CPSC found that $71 \%$ of those in or on the ROV at the time of the crash who were injured and $86 \%$ of those killed were partially or fully ejected from the vehicle [1]. Of the victims in our study, we found that about one-half had been struck or pinned by part of the vehicle-almost all after being ejected. The number struck or pinned in our study may be an underestimate, as documentation in the newspaper reports was sometimes inadequate to make this determination. CPSC data analysis showed that $62 \%$ of those injured and $75 \%$ of those killed had been struck by part of the vehicle after ejection [1].

Clearly the most important factor for decreasing death and injuries in SxS crashes is wearing the seat belt or harness system, if available. In addition, no passengers should be allowed who cannot be properly restrained. The CPSC NPR would require manufacturers to provide a means by which vehicles could not surpass $15 \mathrm{mph}$ unless the driver's seat belt was connected. Considerations to apply similar technology to the passenger seating, especially the front passenger, were contemplated as well. Implementation of these technologies on future vehicles could have a significant effect on decreasing ROV-related deaths and injuries.

\subsubsection{Lighting}

SxSs are typically equipped with lights, but it was still surprising to see that nearly two-fifths of ROV crashes in the study occurred during compromised light conditions, all at night except for one occurring at dusk. Certainly, off-road driving is particularly hazardous at night when it may be even more difficult to appreciate changes in terrain and the presence of obstacles.

\subsubsection{Roadway Riding}

Although SxSs are designed for off-road use only, over half of the ROV crashes in our study occurred on roadways. Interestingly, only one in five SxS crashes on roadways involved another motorized vehicle. Studies on ATV crashes have found that over two-thirds of fatalities and three-fourths of injuries on roadways do not involve another motorized vehicle [19,24].

As clearly stated by the manufacturer [31], SxSs are not designed for roadway use. Whereas automobile tires are made to continually grip and release roadway surfaces, SxS tires are designed to grab off-road terrain and can unpredictably interact with roadway surfaces. Exacerbated by higher 
roadway speeds, the tires may unevenly grab the road, especially after hitting bumps or ruts on unpaved surfaces, leading to loss of control. Although our data source did not provide information on roadway type, a previous study on ATVs found that riding on both paved and unpaved roads represented increased risk [26].

In addition, automobiles have a rear differential which allows the outside wheels to travel faster than the inside wheels which facilitates turning. Many SxSs have a locked rear differential that results in the vehicles requiring a wider turning radius and makes it more difficult to negotiate turns and curves, especially at the maximum speeds many ROVs can travel. Although many newer ROVs have the ability to unlock the rear differential (sometimes called "turf mode" to decrease cutting up the lawn), many operators may not realize that if they do travel on roads, they might benefit from unlocking the rear differential or putting the vehicle in "turf mode."

\subsection{Fatalities}

Twenty-eight of the SxS cases reported in the newspapers of the nine Midwest/Great Plains states were fatalities. Of these deaths: over two-fifths were $<16$ years of age, one-half occurred on roads, and nearly three-quarters were ejected as part of the crash mechanism. Common features of deaths included a younger operator, likely unbelted with a rollover resulting in the victim being ejected and then struck or pinned by the vehicle.

\subsection{Limitations}

Our study was limited in that it included only nine U.S. states, and thus our results may not be generalizable to other U.S. geographical regions or to other countries. Moreover, the number of cases available for analysis was limited and desired data variables were not always provided in newspaper articles. For example, the lack of helmet and seat belt use documentation precluded any analysis of these variables. Missing data could also have an impact on our analysis. In addition, this report is not a comprehensive compilation of all SxS crashes and injuries that occurred in the states studied. Only those crashes reported in newspapers were included. These newspaper articles are likely to capture fatalities and more severe injuries, but even severe crashes may not always reach media attention. Crashes in which police or other enforcement officers become involved may have a greater chance of being reported. We also hypothesize that roadway crashes would have a greater likelihood of reaching media as compared to incidents occurring off-road, and crashes involving children may also be more likely to be considered newsworthy. Although there may be some biases related to which crashes are reported, there is no obvious reason why these biases would be substantially different for ATVs and SxSs, both off-road vehicles.

The use of newspaper clippings for epidemiologic studies of SxS crashes clearly has many limitations, and the information reported by journalists, who lack safety training, may be less than that desired. However, newspaper articles have been found useful in the surveillance and epidemiology of a number of injury mechanisms, and in identifying emerging problems. Off-road vehicle-related research is often difficult with regards to identifying the exact type of vehicle involved, and the crash mechanism is often imperfectly described and lacking in details in many primary sources including medical records. These challenges provide the rationale for using many sources to fully understand the problem of SxS-related deaths and injuries, including the newspaper clippings reported on in this study.

\section{Conclusions}

A high proportion of SxS crashes in newspaper reports in the Midwest/Great Plans region of the U.S. documented injured victims being ejected and struck/pinned by the vehicle. Although ROVs and many UTVs have rollover protective structures, lack of safety belt use is likely reducing their benefit. Children suffer a very high percentage of the deaths and injuries related to SxSs, often while driving. Children should be prohibited from operating SxSs, and should not be passengers unless they 
can be properly belted with their backs against the seat, feet on the floor, and able to easily hold onto the hand grip from that position. Given the relative "newness" of these vehicles, education efforts are needed to inform consumers of their dangers. Moreover, proposed standards as initiated by the CPSC to engineer improved vehicle safety regarding lateral stability, vehicle handling and occupant protection performance should be adopted.

Acknowledgments: Funding for these studies was provided by the University of Iowa, Department of Emergency Medicine. Additional funding was provided by CDC/NIOSH Great Plains Center for Agricultural Health, U54OH007548, and Iowa Fatality Assessment and Control Evaluation (FACE) Program/Iowa Department of Public Health, U60OH008460. No funds were received for covering the cost to publish in open access.

Author Contributions: C.A.J., G.M.D., and K.K.H. participated in the study's conceptualization and design. C.A.J. and G.M.D. obtained the newspaper reports, developed the coding keys, and supervised variable coding. K.K.H., G.M.D. and C.A.J. provide database management and performed data analysis. C.A.J. and G.M.D. were primarily responsible for writing the manuscript and its completion.

Conflicts of Interest: The authors declare no conflict of interest and have no financial disclosures to report. The founding sponsors had no role in the design of the study; in the collection, analyses, or interpretation of data; in the writing of the manuscript, and in the decision to publish the results.

\section{Abbreviations}

$\begin{array}{ll}\text { SxS } & \text { side-by-side } \\ \text { ROV } & \text { recreational off-highway vehicle } \\ \text { mph } & \text { miles per hour } \\ \text { UTV } & \text { utility task vehicle } \\ \text { SAE } & \text { Society of Automotive Engineering } \\ \text { ROPS } & \text { rollover protective structure } \\ \text { ATV } & \text { all-terrain vehicle } \\ \text { CPSC } & \text { Consumer Product Safety Commission } \\ \text { OR } & \text { unadjusted odds ratio } \\ \text { CI } & \text { confidence intervals }\end{array}$

\section{References}

1. U.S. Consumer Product Safety Commission. Notice of Proposed Rulemaking. 16 CFR Part 1422. Safety standard for recreational off-highway vehicles (ROVs). Fed. Regist. 2014, 79, 68964-69031.

2. Imlay, M. Utility Task Vehicles by the Numbers. Available online: https://www.sema.org/sema-news/2014/ 07/utility-task-vehicles-by-the-numbers (accessed on 30 October 2015).

3. Wilson, L. Side-by-side off-Road Vehicles: Rollover Occupant Protection-Standards and Vehicle Classification. Winter Meeting of the ANB45(1) Rollover subcommittee Sponsored by the ANB45 Occupant Protection Committee of the Transport Research Board, January 2015. Available online: http://anb45.hsrc.unc.edu/rollover/documents/Winter_2015/ppt/LW-TRB_SxS-Rollover_Protection _and_Standards.pdf (accessed on 30 October 2015).

4. Ahrens, J.; Bengel, P. First Rider-Polar Opposites: Two New, Vastly Different Machines from Polaris. ATV \& SxS Illustrated. Available online: http://atvillustrated.com/content/first-ride-polar-opposites (accessed on 30 October 2015).

5. Specialty Vehicle Institute of America (SVIA)/ATV Safety Insititute. Tips and Practice Guide for the All-Terrain Vehicle Rider. Revised April 2014. Available online: http://www.atvsafety.org/downloads/ ATV_Riding_Tips.pdf (accessed on 30 October 2015).

6. Baullinger, J.; Quan, L.; Bennett, E.; Cummings, P.; Williams, K. Use of Washington State newspapers for submersion injury surveillance. Inj. Prev. 2001, 7, 339-342. [CrossRef] [PubMed]

7. Berchialla, P.; Scarinzi, C.; Snidero, S.; Rahim, Y.; Gregori, D. Information extraction approaches to unconventional data sources for "Injury Surveillance System": The case of newspapers clippings. J. Med. Syst. 2012, 36, 475-481. [CrossRef] [PubMed] 
8. Denton, J.F.; Fabricius, W.V. Reality check: Using newspapers, police reports, and court records to assess defensive gun use. Inj. Prev. 2004, 10, 96-98. [CrossRef] [PubMed]

9. Genovesi, A.L.; Donaldson, A.E.; Morrison, B.L.; Olson, L.M. Different perspectives: A comparison of newspaper articles to medical examiner data in the reporting of violent deaths. Accid. Anal. Prev. 2010, 42, 445-451. [CrossRef] [PubMed]

10. Huitink, G.; Struttmann, T.; Perkins, D. Farm injuries in Arkansas 1990-2000. J. Ark. Med. Soc. 2005, 101, 304-307. [PubMed]

11. Kool, B.; Ameratunga, S. Fire-related child deaths: What do newspaper case reports tell us? J. Paediatr. Child Health 2003, 39, 654-656. [CrossRef] [PubMed]

12. Nasrullah, M.; Muazzam, S. Newspaper reports: A source of surveillance for burns among women in Pakistan. J. Public Health 2010, 32, 245-249. [CrossRef] [PubMed]

13. Ozegovic, D.; Voaklander, D.C. What we are not talking about: An evaluation of prevention messaging in print media reporting on agricultural injuries and fatalities. Am. J. Ind. Med. 2011, 54, 603-608. [CrossRef] [PubMed]

14. Rainey, D.Y.; Runyan, C.W. Newspapers: A source for injury surveillance? Am. J. Public Health 1992, 82, 745-746. [CrossRef] [PubMed]

15. Rosales, M.; Stallones, L. Coverage of motor vehicle crashes with injuries in U.S. newspapers, 1999-2002. J. Saf. Res. 2008, 39, 477-482. [CrossRef] [PubMed]

16. Saluja, G.; Brenner, R.A.; Trumble, A.C.; Smith, G.S.; Schroeder, T.; Cox, C. Swimming pool drownings among US residents aged 5-24 years: Understanding racial/ethnic disparities. Am. J. Public Health 2006, 96, 728-733. [CrossRef] [PubMed]

17. Shai, D.; Lupinacci, P. Fire fatalities among children: An analysis across Philadelphia's census tracts. Public Health Rep. 2003, 118, 115-126. [CrossRef]

18. Turgut, A.; Turgut, T. A population-based study on deaths by drowning incidents in Turkey. Int. J. Inj. Contr. Saf. Promot. 2014, 21, 61-67. [CrossRef] [PubMed]

19. Denning, G.; Jennissen, C.; Harland, K.; Ellis, D.; Buresh, C. All-terrain vehicles (ATVs) on the road: A serious traffic safety and public health concern. Traffic Inj. Prev. 2013, 14, 78-85. [CrossRef] [PubMed]

20. Denning, G.M.; Jennissen, C.A.; Harland, K.K.; Ellis, D.G.; Buresh, C.T. Off-highway vehicle parks: Combining environment, knowledge, and enforcement for all-terrain vehicle injury prevention. Accid. Anal. Prev. 2013, 52, 64-70. [CrossRef] [PubMed]

21. U.S. Consumer Product Safety Commission. 2013 Annual Report of ATV-Related Deaths and Injuries. Available online: http://wwwcpscgov//Global/Research-and-Statistics/Injury-Statistics/Sports-andRecreation/ATVs/2013-ATV-Annual-Rpt-of-ATV-Related-Deaths-Injuriespdf (accessed on 23 October 2015).

22. Baker, J. Taking the World by Storm: A Brief History of UTVs and their Progression. 14 July 2014. Available online: https://www.rockymountainatvmc.com/rm-rider-exchange/taking-world-storm-brief-utv-history/ (accessed on 30 October 2015).

23. Levin, M. Yamaha Faces Hundreds of Lawsuits over off-Road Rhino Injuries, Deaths. Special to the Oregonian. 27 September 2010. Available online: http://www.oregonlive.com/business/index.ssf/ 2010/09/yamaha_faces_hundreds_of_lawsu.html (accessed on 30 October 2015).

24. Denning, G.; Harland, K.; Ellis, D.; Jennissen, C. More fatal all-terrain vehicle crashes occur on the roadway than off: Increased risk-taking characterises roadway fatalities. Inj. Prev. 2013, 19, 250-256. [CrossRef] [PubMed]

25. Denning, G.M.; Harland, K.K.; Jennissen, C.A. Age-Based Risk Factors for Pediatric ATV-Related Fatalities. Pediatrics 2014, 134, 1094-1102. [CrossRef] [PubMed]

26. Denning, G.M.; Jennissen, C.A. All-Terrain Vehicle Fatalities on Paved Roads, Unpaved Roads, and Off-Road: Evidence for Informed Roadway Safety Warnings and Legislation. Traffic Inj. Prev. 2015. [CrossRef] [PubMed]

27. Polaris Industries I. RANGER XP 900 Owner's Manual 2012. Available online: http:/ / www.manualslib.com/ manual/742250/Polaris-Ranger-Xp-900.html?page=6 - manual (accessed on 30 October 2015).

28. Polaris Industries I. 2014 RZR 900/RZR 4900 Owner's Manual. 2013. Available online: http:/ /www.manualslib.com/manual/945700/Polaris-2014-Rzr-9002014-Rzr-4-900.html?page=7-manual (accessed on 30 October 2015). 
29. Kawasaki Heavy Industries L. Mule 4010 Trans4x4 Utility Vehicle Owner's Manual. 2012. Available online: http:/ / www.manualslib.com/manual/803081/Kawasaki-Mule-4010-Trans-4x4.html?page=7-manual (accessed on 30 October 2015).

30. Grzebieta, R.; Rechnitzer, G.; Simmons, K. The Quad Bike Performance Project. Dynamic Handling Test Results. Available online: http://www.tars.unsw.edu.au/research/Current/Quad-Bike_Safety/ ReportsQuad_Project_Final_Report2_Dynamic_Handling_Tests_Results_Jan-2015.pdf (accessed on 28 October 2015).

31. Specialty Vehicle Institute of America (SVIA). Position in Opposition to On-Road Operation of ATVs. Available online: http://www.svia.org/Downloads/PositionPaperOpposingOn-RoadUse.pdf (accessed on 28 April 2015).

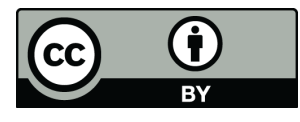

(c) 2016 by the authors; licensee MDPI, Basel, Switzerland. This article is an open access article distributed under the terms and conditions of the Creative Commons by Attribution (CC-BY) license (http://creativecommons.org/licenses/by/4.0/). 